Research Paper

\title{
Co-infection Of Ureaplasma urealyticum And Human Papilloma Virus In Asymptomatic Sexually Active Individuals
}

Sang Il Kim¹, Joo Hee Yoon ${ }^{1}$, Dong Choon Park ${ }^{1}$, Dong Sup Lee², Seung Ju Lee², Hyun Sop Choe², Jin Hwi $\mathrm{Kim}^{3}$, Tae Chul Park ${ }^{3}$, Sung Jong Lee ${ }^{\circledR}$

1. Department of Obstetrics and Gynecology, College of Medicine, St. Vincent's Hospital, The Catholic University of Korea, Suwon, Republic of Korea

2. Department of Urology, College of Medicine, St. Vincent's Hospital, The Catholic University of Korea, Suwon, Republic of Korea

3. Department of Obstetrics and Gynecology, College of Medicine, Uijeongbu St. Mary Hospital, The Catholic University of Korea, Uijeongbu, Republic of Korea

$\square$ Corresponding author: Sung Jong Lee. Department of Obstetrics and Gynecology, College of Medicine, St. Vincent's Hospital, The Catholic University of Korea, Jungbu-daero 93, Paldal-gu, Suwon, Gyeonggi-do 442-723, Republic of Korea; Tel: +82-31-249-8304, Fax: +82-31-254-7481, E-mail: orlando@catholic.ac.kr

(c) Ivyspring International Publisher. This is an open access article distributed under the terms of the Creative Commons Attribution (CC BY-NC) license (https://creativecommons.org/licenses/by-nc/4.0/). See http://ivyspring.com/terms for full terms and conditions.

Received: 2018.04.06; Accepted: 2018.05.27; Published: 2018.06.12

\begin{abstract}
This study aimed to determine the role of asymptomatic bacterial sexually transmitted infections (STIs), such as Chlamydia trachomatis (Ct), Mycoplasma genitalium (Mg), Mycoplasma hominis (Mh), and Ureaplasma urealyticum $(\mathrm{Uu})$ in human papillomavirus (HPV) infection.

In total, 264 asymptomatic outpatients aged between 21 and 80 years were prospectively enrolled in this study during routine gynecological screening tests. Specimens collected with a Cervex Brush were routinely analyzed with the Hybrid Capture 2 assay for HPV. Simultaneously, a specimen obtained with an endocervical swab was used to detect $\mathrm{Ct}$ and $\mathrm{Mg}$ with a monoplex real-time polymerase chain reaction (PCR) and to confirm Mh and Uu with a Mycoplasma IST 2 kit.

The detection rates (\%) of HPV, Ct, Mg, Mh, and Uu were 82/264 (31.1), 6/264 (2.3), 5/264 (1.9), 16/264 (6.1), and 95/264 (36.0), respectively. Of $95 \mathrm{Uu}, 32(33.7 \%)$ showed high density colonization (HDC, $\geq 10^{4}$ color-changing units $/ \mathrm{mL})$. HDC-Uu was significantly associated with HPV infection ( $p=0.014$, chi-square test). $M g$ infection and $M h$ infection were not associated with HPV infection $(p=0.981$ and $p=0.931$, chi-square test). Age was not associated with HPV infection or bacterial infection.

Our data suggested that asymptomatic HDC-Uu was closely associated with HPV infection. Therefore, simultaneous evaluation for Uu and HPV should be performed during gynecological screening, even in asymptomatic individuals.
\end{abstract}

Key words: Mycoplasma; Ureaplasma urealyticum; human papillomavirus

\section{Introduction}

Human papillomavirus (HPV) has been identified the etiologic agent of warts, cervical intraepithelial neoplasia (CIN), and cervical cancer. Among sexually transmitted infections (STIs), only HPV infection is known to be a major cause of cervical cancer. ${ }^{1}$ However, cervical carcinogenesis is not facilitated by HPV infection alone, but it also associated with environmental factors, such as multiple sex partners and sexually transmitted diseases. $^{2}$
A Recent study investigated the relationships between HPV and vaginal bacteria, including Mycoplasma spp. and Chlamydia trachomatis (Ct), and found that HPV was associated with $C t$ and Ureaplasma urealyticum $(U u){ }^{3}$ Therefore, detection of Mycoplasma or Chlamydia infection may play a role in decreasing the prevalence of cervical cancer. Althouogh, the majority of individuals infected with Chlamydia and Mycoplasma were asymptomatic, ${ }^{4,5}$ they could be carriers of Chlamydia and Mycoplasma infections in the community. A recent study 
conducted in Korea showed an incidence (\%) of 5.6, 0.3, 22.1 and 11.6, respectively, for $C t, M$. genitalium $(M g), U u$, and $M$. hominis $(M h)$ in asymptomatic individuals. ${ }^{6}$ However, to our knowledge, no epidemiologic study has evaluated the association between asymptomatic bacterial STIs and HPV infection in sexually active individuals.

The aim of this study was to evaluate the relationship between bacterial STI and HPV infection among asymptomatic sexually active women.

\section{Materials and methods}

\section{Study population}

From a group of asymptomatic women who visited a gynecological outpatient clinic for routine screening between January 2012 and August 2017, 264 volunteers were enrolled in this study. Informed consent was obtained from all women participating in the study. The institutional review board of The Catholic University of Korea approved this study (No. VC15RISI0094). Cervical specimens for high-risk HPV detection and identification of other microorganisms were taken from the asymptomatic volunteers during a routine pelvic examination. Cytology was graded according to the Bethesda system, using standard forms, and was classified as negative, low-grade (atypical squamous cells of undetermined significance, atypical glandular cells of undetermined significance, low-grade squamous intraepithelial lesion), or high-grade (atypical squamous cells cannot exclude high- grade squamous intraepithelial lesion). ${ }^{7}$

All women aged between 21 and 80 years who engaged in sexual activity at least once a month were eligible. Exclusion criteria were: 1) any urogenital symptoms, such as vaginal and/or urethral discharge, itching at the external genitalia, dyspareunia, dysuria, vaginal spotting, or hematuria; 2) antimicrobial treatment within 1 month prior to the present study; 3) recently diagnosed cervical disease within 6 months prior to the present study; 4) current pregnancy.

All participants were interviewed regarding obstetric history and the number of sexual partners in the prior 2 years.

\section{HPV detection}

Specimens were collected with a Cervex Brush (Rovers Medical Devices B.V., The Netherlands) and rinsed with PreservCyt fixative solution (Cytyc Corp., Roxborough, MA, USA). Specimens were placed in denatured alcohol at $65 \pm 2^{\circ} \mathrm{C}$ for $45 \mathrm{~min}$, and mixed with a 1:25 diluted HPV probe (for high-oncogenic risk types $16,18,31,33,35,39,45,51,52,56,58,59$, and 68 ) in a 96-well plate with the help of a rotary shaker at $1,100 \mathrm{rpm}$. The mixture was incubated at $65 \pm 2^{\circ} \mathrm{C}$ for $60 \mathrm{~min}$. The hybridized mixture was moved a Capture micro-plate (Digene Corp., Gaithersburg, MD, USA), with shaking at $1,100 \mathrm{rpm}$ at $20-25^{\circ} \mathrm{C}$ for 60 $\mathrm{min}$. Finally, the conjugation process was performed by adding the detection reagent (CDP-Star ${ }^{\circledR}$, Tropix, Inc., MA, USA) to the Capture micro-plate. After the washing process, the test result was reported in relative light units using a DML 2000 Luminometer (Qiagen, Crawley, UK).

\section{Detection of other microorganisms}

The swab specimen in the collection tube was equilibrated to room temperature and mixed by vortexing. After centrifugation at $13,000 \mathrm{rpm}$ for 10 min, the supernatant was discarded and the pellet was re-suspended in $1 \mathrm{ml}$ of $1 \times$ phosphate-buffered saline by vortexing thoroughly to re-dissolve and disperse the sample. The mixed specimen was transferred to $1.5 \mathrm{ml}$ Eppendorf tubes. DNA was then extracted from the pretreated specimens using the QIAamp ${ }^{\circledR}$ DNA Mini Kit (QIAGEN, Hilden, Germany), according to the manufacturer's instructions. $\mathrm{Ct}$ and $\mathrm{Mg}$ were detected with a monoplex polymerase chain reaction (PCR) using Seegene DPOTM technology. ${ }^{8}$ PCR amplification was performed with the Seeplex ${ }^{\circledR}$ C. trachomatis Detection kit and Seeplex ${ }^{\circledR}$ M. genitalium Detection kit (Seegene, Seoul, Korea) according to the manufacturer's instructions.

Both $M h$ and $U u$ were detected using the commercially available Mycoplasma IST 2 kit (bioMérieux, Marcy-l'Etoile, France). Using this kit, we detected $M h$ and/or $U u$ at a cut-off value of $10^{4}$ color-changing units $(\mathrm{CCU}) / \mathrm{mL}$. A positive test was indicated by a change in broth color from yellow to red (urea for $U u$ and arginine for $M h$ ). An endocervical swab specimen was inoculated into the R1 solution (transport medium) according to the manufacturer's instructions, then combined with a vial of R2 (lyophilized growth medium) and vortexed. A $55-\mu \mathrm{L}$ aliquot of the solution was dispensed into each of 22 test wells on the strip. Two drops of mineral oil were added to each well. The strips were incubated at $37.8^{\circ} \mathrm{C}$ for $24-48 \mathrm{~h}$. Antimicrobial susceptibility against doxycycline, josamycin, ofloxacin, erythromycin, tetracycline, ciprofloxacin, azithromycin, clarithromycin and pristinamycin was also tested using this commercial kit.

However, U. paroum (biovar 1) and $U u$ (biovar 2) could not be discriminated with this kit. Therefore, we used $U u$ for both biovars as in previous research. ${ }^{9}$

\section{Statistical analysis}

SPSS ${ }^{\circledR}$ software (SPSS 15.0, SPSS, Chicago, IL, USA) was used for the statistical analysis. Student's 
$t$-test, the chi-squared test, and Fisher's exact test, were used for statistical evaluations of the associations between groups using nominal data. Logistic regression was used for multivariate analysis and $p<0.05$ was considered statistically significant.

\section{Results}

The mean age of participants was $50.76 \pm 11.04$ years and the mean body mass index $\left(\mathrm{kg} / \mathrm{m}^{2}\right)$ was $23.04 \pm 4.19$. Baseline participant characteristics are presented in Table 1. Among epidemiologic factors, 2 or more sexual partners in the prior 2 years showed a greater association with current HPV infection than 1 partner ( $p=0.001$, chi-square test). Obstetric history was not significantly associated with current HPV infection.

The incidences (\%) of HPV, Ct, Mg, Uu $\left(<10^{4}\right.$ $\mathrm{CCU} / \mathrm{mL}$ ), high-density colonization (HDC)-Uu $\left(>10^{4}\right.$ $\mathrm{CCU} / \mathrm{mL}), \mathrm{Mh}\left(<10^{4} \mathrm{CCU} / \mathrm{mL}\right)$, and HDC-Mh $\left(>10^{4}\right.$ $\mathrm{CCU} / \mathrm{mL}$ ) in the present study was 31.1, 2.3, 1.9, 23.9, 12.1, 4.9, and 1.1, respectively. Among the 264 asymptomatic volunteers, HPV tested positive in 82 $(31.1 \%)$ and $69(26.1 \%)$ had abnormal cytology. HPV infection and both low- and high-grade cytologic abnormalities, were not associated with patient age.
Bacterial infections were also not related to patient age. The distribution of HPV infection, cytologic abnormalities, and bacterial infections according to age is shown in Table 2 .

Two Ct infections $(2 / 6)$ were found in the HPV-infected group ( $p=0.903$, chi-square test). HDC-Uu $\left(>10^{4} \mathrm{CCU} / \mathrm{mL}\right)$ was significantly associated with HPV infection ( $p=0.014$, chi-square test). Even after adjusting for confounding epidemiologic factors, such as multiple sexual partners ( $\geq 3)$, HDC-Uu was still significantly associated with HPV infection $\left(p=0.045\right.$, logistic regression analysis). $U u \quad\left(<10^{4}\right.$ $\mathrm{CCU} / \mathrm{mL}$ ) was not associated with HPV infection ( $p=0.284$, chi-square test). $M g$ and $M h$ (both $<10^{4}$ $\mathrm{CCU} / \mathrm{mL}$ ) were also not associated with HPV infection $(p=0.158$ and $p=0.981$, respectively, chi-square test). The distribution of each microorganism is shown according to the presence of HPV infection in Table 3.

Antimicrobial susceptibility testing of $U u$ showed that the microorganisms were resistant to fluoroquinolones, such as ofloxacin and ciprofloxacin. Meanwhile, $M h$ tended to be resistant to macrolides such as erythromycin, azithromycin and clarithromycin (Table 4).

Table 1. Baseline characteristics of study population $(\mathrm{N}=264)$

\begin{tabular}{|c|c|c|c|c|c|}
\hline & HPV negative $(n=182)$ & HPV positive $(n=82)$ & Total $(n=264)$ & OR & $p$-value, $95 \%$ CI \\
\hline Age (mean) & $51.5 \pm 8.06$ & $49.11 \pm 12.55$ & $50.76 \pm 11.04$ & & $0.376 \ddagger,-2.234 \sim 5.865$ \\
\hline \multicolumn{6}{|l|}{ Number of partners } \\
\hline 1 partner & $155(85.2 \%)$ & $39(47.6 \%)$ & $194(73.5 \%)$ & 1.00 & \\
\hline 2 partners & $14(7.7 \%)$ & $20(24.4 \%)$ & $34(12.9 \%)$ & $5.678^{*}$ & $0.001 \$, 2.634 \sim 12.24$ \\
\hline 3 or more partners & $13(7.1 \%)$ & $23(28.0 \%)$ & $36(13.6 \%)$ & $7.032^{*}$ & $0.001 \S, 3.270 \sim 15.12$ \\
\hline \multicolumn{6}{|l|}{ Parity } \\
\hline Nulliparous & $43(23.6 \%)$ & $22(26.8 \%)$ & $65(24.6 \%)$ & 1.00 & \\
\hline Multiparous & $139(76.4 \%)$ & $60(73.2 \%)$ & $199(75.4 \%)$ & $1.54^{*}$ & $0.330 \$, 0.641 \sim 3.715$ \\
\hline Abortion & $25(13.7 \%)$ & $23(28.0 \%)$ & $48(18.2 \%)$ & $2.29+$ & $0.198 \$, 0.752 \sim 6.948$ \\
\hline
\end{tabular}

Each mean data was presented with standard deviation

$\mathrm{OR}^{*}$ is the odds ratio compared with the first category, and OR ${ }^{\dagger}$ is the odds ratio between HPV negative and positive group.

$p$-value and $p$-value ${ }^{\S}$ were measured by t-student test and Chi-square test, respectively.

Table 2. Characteristics of human papillomavirus infection, cervical cytology and sexually transmitted bacterial infection by age $(\mathrm{N}=264)$

\begin{tabular}{|c|c|c|c|c|c|c|c|}
\hline Age distribution & & & $21 \sim 50(n=139)$ & $51 \sim 80(n=125)$ & OR & $p$-value & $95 \% \mathrm{CI}$ \\
\hline \multicolumn{8}{|l|}{$\mathrm{HPV}$} \\
\hline & HPV negative ( $n=182)$ & & $93 / 139(66.9 \%)$ & $89 / 125(71.2 \%)$ & 1.00 & & \\
\hline & HPV positive $(\mathrm{n}=82)$ & & $46 / 139(33.1 \%)$ & $36 / 125(28.8 \%)$ & 1.223, & $0.4516^{*}$ & $0.724-1.652$ \\
\hline \multicolumn{8}{|l|}{ Cytology } \\
\hline & Negative cytology $(n=195)$ & & $101 / 139(72.6 \%)$ & $94 / 125(75.2 \%)$ & 1.00 & & \\
\hline & Low grade abnormality $(n=28)$ & & $14 / 139(10.1 \%)$ & $14 / 125(11.2 \%)$ & 0.888 & $0.766^{*}$ & $0.406-1.945$ \\
\hline & High grade abnormality ${ }^{\ddagger}(n=41)$ & & $24 / 139(17.3 \%)$ & $17 / 125(13.6 \%)$ & 1.326 & $0.412^{*}$ & $0.675-2.603$ \\
\hline \multicolumn{8}{|l|}{ Bacterial infection } \\
\hline & Chlamydia trachomatis $(n=6)$ & & $4 / 139(2.9 \%)$ & $2 / 125(1.6 \%)$ & 1.822 & $0.487^{*}$ & $0.328-10.13$ \\
\hline & Mycoplasma genitalium $(n=5)$ & & $4 / 139(2.9 \%)$ & $1 / 125(0.8 \%)$ & 3.674 & $0.216^{*}$ & $0.405-33.34$ \\
\hline & Ureaplasma urealyticum $(n=95)$ & $<10^{4} \mathrm{CCU} / \mathrm{ml}(\mathrm{n}=63)$ & $32 / 139(23.0 \%)$ & $31 / 125(24.8 \%)$ & 0.907 & $0.735^{*}$ & $0.515-1.598$ \\
\hline & & $>10^{4} \mathrm{CCU} / \mathrm{ml}(\mathrm{n}=32)$ & $18 / 139(12.9 \%)$ & $14 / 125(11.2 \%)$ & 1.179 & $0.664^{*}$ & $0.560-2.483$ \\
\hline & Mycoplasma hominis $(n=16)$ & $<10^{4} \mathrm{CCU} / \mathrm{ml}(\mathrm{n}=13)$ & $4 / 139(2.9 \%)$ & $9 / 125(7.2 \%)$ & 0.382 & $0.105^{*}$ & $0.115-1.273$ \\
\hline & & $>10^{4} \mathrm{CCU} / \mathrm{ml}(\mathrm{n}=3)$ & $1 / 139(0.7 \%)$ & $2 / 125(1.6 \%)$ & 0.446 & $0.500^{*}$ & $0.040-4.978$ \\
\hline
\end{tabular}

Data in bracket was presented as positive cases/all cases, percentage

* Chi-squared test; +Low grade: ASCUS, AGUS, LSIL; ‡High grade: ASC-H, HSIL 
Table 3. Relationship between sexually transmitted bacterial infections and HPV infection ( $N=264)$

\begin{tabular}{|c|c|c|c|c|}
\hline Bacterial infection & & HPV negative $(n=182)$ & HPV positive $(n=82)$ & $p$-value, OR, $95 \% \mathrm{CI}$ \\
\hline C. trachomatis $^{\dagger}(\mathrm{n}=6)$ & & $4(2.2 \%)$ & $2(2.4 \%)$ & $0.903^{*}, 1.1130 .199-6.202$ \\
\hline M. genitalium ${ }^{\ddagger}(\mathrm{n}=5)$ & & $2(1.1 \%)$ & $3(3.7 \%)$ & $0.158^{*}, 3.418,0.559-20.86$ \\
\hline \multirow[t]{2}{*}{ U. urealyticum ${ }^{\S}(\mathrm{n}=95)$} & $<10^{4} \mathrm{CCU} / \mathrm{ml}(\mathrm{n}=63)$ & $40(22.0 \%)$ & $23(28.0 \%)$ & $0.284^{*}, 1.384,0.762-2.512$ \\
\hline & $>10^{4} \mathrm{CCU} / \mathrm{ml}(\mathrm{n}=32)$ & $16(8.8 \%)$ & $16(19.5 \%)$ & $0.014^{*}, 2.515,1.189-5.322$ \\
\hline \multirow[t]{2}{*}{ M. hominis" $(\mathrm{n}=16)$} & $<10^{4} \mathrm{CCU} / \mathrm{ml}(\mathrm{n}=13)$ & $9(4.9 \%)$ & $4(4.9 \%)$ & $0.981^{*}, 0.985,0.294-3.299$ \\
\hline & $>10^{4} \mathrm{CCU} / \mathrm{ml}(\mathrm{n}=3)$ & $2(1.1 \%)$ & $1(1.2 \%)$ & $0.931^{*}, 1.111,0.099-12.44$ \\
\hline
\end{tabular}

Each value was presented as negative/positive.

${ }^{*}$ Chi-squared test

+Chlamydia trachomatis

$¥$ Mycoplasma genitalium

sUreaplamsa urealyticum

"Mycoplasma hominis

Table 4. Antimicrobial susceptibility pattern of Ureaplasma urealyticum and Mycoplasma hominis in asymptomatic sexually active women $\left(\mathrm{N}=111^{*}\right)$

\begin{tabular}{|c|c|c|c|c|c|c|}
\hline & \multicolumn{3}{|c|}{ Ureaplasma urealyticum $(\mathrm{n}=95)$} & \multicolumn{3}{|c|}{ Mycoplasma hominis $(\mathrm{n}=16)$} \\
\hline & St $(\%)$ & $\mathrm{I} \ddagger(\%)$ & $\mathrm{R}^{\S}(\%)$ & $\mathrm{S}+(\%)$ & $\mathrm{I}^{\ddagger}(\%)$ & $\mathrm{R}^{\S}(\%)$ \\
\hline Doxycycline & 95(100.0) & $0(0.0)$ & $0(0.0)$ & $16(100.0)$ & $0(0.0)$ & $0(0.0)$ \\
\hline Josamycin & $95(100.0)$ & $0(0.0)$ & $0(0.0)$ & $16(100.0)$ & $0(0.0)$ & $0(0.0)$ \\
\hline Ofloxacin & $38(40.0)$ & $48(50.5)$ & $8(8.4)$ & $14(87.5)$ & $2(12.5)$ & $0(0.0)$ \\
\hline Erythromycin & $83(87.4)$ & $10(10.5)$ & $2(2.1)$ & $0(0.0)$ & $0(0.0)$ & $16(100.0)$ \\
\hline Tetracycline & $95(100.0)$ & $0(0.0)$ & $0(0.0)$ & $16(100.0)$ & $0(0.0)$ & $0(0.0)$ \\
\hline Ciprofloxacin & $10(10.5)$ & $39(41.1)$ & $46(48.4)$ & $11(68.8)$ & $2(12.5)$ & $2(12.5)$ \\
\hline Azithromycin & $77(81.0)$ & $18(18.9)$ & $0(0.0)$ & $0(0.0)$ & $4(25.0)$ & $12(75.0)$ \\
\hline Clarithromycin & $93(97.9)$ & $0(0.0)$ & $2(2.1)$ & $0(0.0)$ & $0(0.0)$ & $16(100.0)$ \\
\hline Pristinamycin & 95(100.0) & $0(0.0)$ & $0(0.0)$ & $16(100.0)$ & $0(0.0)$ & $0(0.0)$ \\
\hline
\end{tabular}

\section{Discussion}

The most important finding of this study was that HDC-Uu was associated with HPV infection in asymptomatic, sexually active woman at all age. Verteramo et al. suggested that $C t$ and $U u \quad\left(>10^{4}\right.$ $\mathrm{CCU} / \mathrm{mL}$ ) may be risk factors for HPV infection in asymptomatic patients. ${ }^{3}$ Lukic et al. emphasized that $U u\left(>10^{4} \mathrm{CCU} / \mathrm{mL}\right)$ in asymptomatic woman could be a cofactor in HPV infection and may exert a negative influence on cervical cytology. ${ }^{2}$

This result was also similarly observed in symptomatic woman. Pisani et al. found parallel positive rates of $U u$ and HPV infection and suggested a synergistic effect between $U u$ and HPV infection in CIN and cervical cancer caused by HPV. ${ }^{10}$

Zhang et al. found that $U u$ was the most common infection among patients with HPV, which supports our result. However, in contrast to our results, there was no significant association between $U u$ and HPV infection. ${ }^{11}$

Other studies suggesting a relationship between HPV infection and $U u$ infection are described in table $5 .{ }^{2,3,10,12-20}$ These studies strongly support an association between $U u$ and HPV infection. Coinfection of $U u$ with HPV contributes to development of CIN. Diagnosis and treatment can be delayed in asymptomatic women, but not in symptomatic women with $U u$ and HPV coinfection. Therefore, HPV testing is suggested in women with $U u$ infection, regardless of symptom status.

The number of sexual partners is a known risk factor for HPV infection, Kataja et al. reported that the number of sexual partners during prior 2 years is the strongest independent risk factor for HPV infections. ${ }^{21}$ In our cohort, we tried to classify participants according to the number of sexual partners in the prior 2 years. Among 264 participants, 34 had 2 partners and 36 had 3 or more partners, which suggested that the cohort in our study consisted of sexually active individuals. Even after adjustment for the number of sexual partners (logistic regression analysis with cut-off at $1-2$ versus 3 or more), HDC-Uu was significantly associated with HPV infection in the present study.

Kataja et al. reported that the risk for HPV infection varied with age, being highest in the 20-29 year old group, and thereafter declining in subsequent 10-year age groups. ${ }^{21}$

However, in our cohort, we found no relationship between age and HPV infection. Moreover, age was not associated with abnormal cytology or bacterial infection. Therefore, asymptomatic infection with HDC-Uu should be eradicated, regardless of age, for the prevention of HPV infection and subsequent CIN. 
Table 5. Relationship between bacterial infection and HPV infection

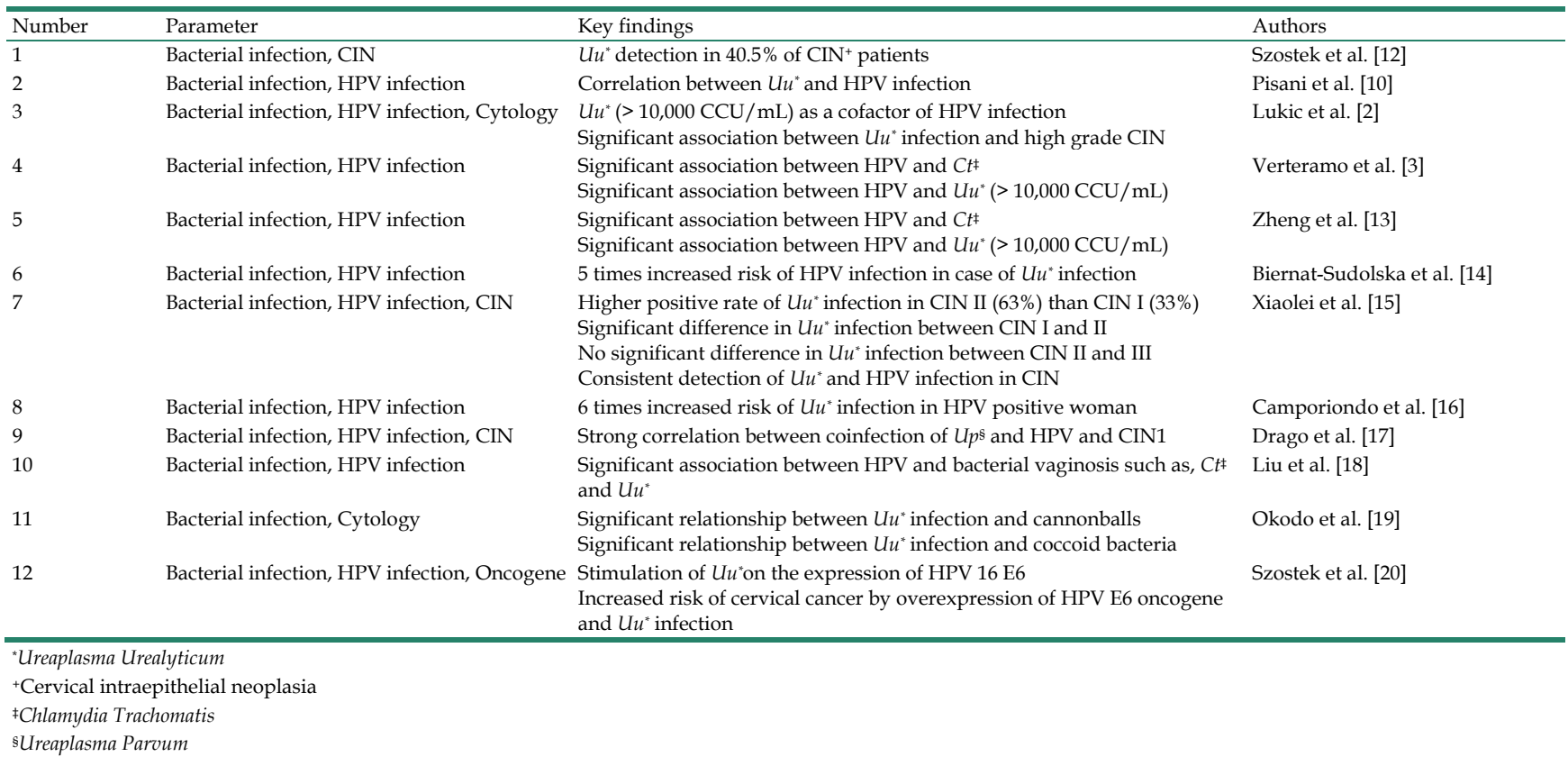

$\mathrm{Ct}$ and $\mathrm{Mg}$ are known to cause STIs. According to Bhatla et al., Ct is not a direct cause of cervical neoplasia, but could be a causative factor in HPV infection. ${ }^{22}$ Several reports showed that the presence of $C t$ negatively affects host cell immunity against $\mathrm{HPV}$, furthermore, $\mathrm{Ct}$ induced micro-abrasion on the cervix that can increase susceptibility to HPV. ${ }^{23,24} \mathrm{~A}$ recent study revealed that the incidence of asymptomatic $C t$ and $U u$ was $5.6 \%$ and $22.1 \%$, respectively, ${ }^{6}$ whereas in this study, the incidence was $2.3 \%$ and $36.0 \%$, respectively. However, only 2 among $6 \mathrm{Ct}$ infections and 3 among $5 \mathrm{Mg}$ infections had HPV infection in our study. These cases were insufficient to determine statistical significance.

In our study, the incidence of asymptomatic $U u$ infection was $36.0 \%$, whereas Zhang et al. reported that the incidence of symptomatic $U u$ infection was $58.7 \% .{ }^{25}$ The incidence rate of asymptomatic $U u$ infection was relatively low. However, asymptomatic $U u$ infection could be a cofactor in HPV infection. ${ }^{2}$ Moreover, coinfection of $U u$ with HPV can contribute to development of CIN. Therefore, HPV testing should be performed in women with $U u$ infection, regardless of symptom status.

Our research showed that, HDC-Uu, an intracellular microorganism, was related to HPV infection in asymptomatic sexually active individuals. This important finding indicates that asymptomatic subjects with potentially harmful bacteria should be treated. We should note that high risk HPV infection is the most important risk factor for cervical cancer. ${ }^{1}$ Therefore, asymptomatic infection with HDC-Uu combined with HPV should be eradicated for the prevention of CIN.
There has been persistently controversy regarding $U u$ as a pathogen in STIs. Therefore, it was unclear as to whether $U u$ colonization should be considered an infection. However, a recent meta-analysis suggested that $U u$ is an etiological agent in STIs..$^{25}$ A recent study also demonstrated that a high density of Ureaplasma may be associated with STIs. ${ }^{26}$ When determining the clinical significance of Ureaplasma infection, the differentiation of colonization and infection is necessary because of the high prevalence in the healthy population (Ureaplasma $70-80 \%$, Mycoplasma 30-40\%). The presence of more than $10^{4} \mathrm{CCU} / \mathrm{mL}$ in a sample is an additional criterion used to distinguish colonization from infection. ${ }^{27}$

Interestingly, our data also indicated that only $U u$ colonization with greater than $10^{4} \mathrm{CCU} / \mathrm{mL}$ was significantly associated with HPV infection.

According to our results of antimicrobial susceptibility testing, $U u$ has a high rate of resistance to fluoroquinolones. Recently, Vargović et al. reported that $78.5 \%$ of $U u$ isolates were sensitive to ofloxacin, in contrast to $98.2 \%$ showing sensitivity to doxycycline. ${ }^{28}$ Susceptibilities of specific species to antimicrobial agents show regional variation according to current trends of antimicrobial use in the community. ${ }^{29}$ Our data showed that sensitivities to ofloxacin and ciprofloxacin were $40.0 \%$ and $10.5 \%$, which were higher than the results reported by Xie et al. (sensitivities to ofloxacin and ciprofloxacin were $22.1 \%$ and $5.8 \%$ ). They presented a decreasing trend of sensitivity of $U u$ to fluoroquinolones, and pointed out that topoisomerase IV ParE subunit plays a role in emerging fluoroquinolone resistance in $U u^{30}$ 
Therefore, if $U u$ is detected in asymptomatic sexually active individuals in an area where susceptibility testing of $U u$ is not available, we recommend consideration of doxycycline or erythromycin (or its derivatives; eg, azithromycin, clarithromycin and pristinamycin) for empirical treatment.

A limitation of this study is that a partner's past sexual history could not be clearly determined. This could represent a strong risk factor for infection with $U u$ and HPV. During the study, it was very difficult to complete the interview about sexual history because all the participants were asymptomatic and some of were reluctant to provide a personal history.

In conclusion, HDC-Uu $\left(>10^{4} \mathrm{CCU} / \mathrm{mL}\right)$ could be a risk factor for HPV infection. We recommend that women infected with $U u$ be treated with doxycycline or erythromycin derivatives as first line agents.

\section{Acknowledgments}

This research was supported by a grant of the Korea Health Technology R\&D Project under the Korea Health Industry Development Institute (KHIDI), funded by the Ministry of Health \& Welfare, Republic of Korea (grant number: HI15C-2915020017).

\section{Competing Interests}

The authors have declared that no competing interest exists.

\section{References}

1. Lee SJ, Yang A, Wu TC, Hung CF. Immunotherapy for human papillomavirus-associated disease and cervical cancer: review of clinical and translational research. J Gynecol Oncol. 2016;27:e51.

2. Lukic A, Canzio C, Patella A, Giovagnoli M, Cipriani P, Frega A, et al. Determination of cervicovaginal microorganisms in women with abnormal cervical cytology: the role of Ureaplasma urealyticum. Anticancer Res. 2006;26:4843-9.

3. Verteramo R, Pierangeli A, Mancini E, Calzolari E, Bucci M, Osborn J, et al. Human Papillomaviruses and genital co-infections in gynaecological outpatients. BMC Infect Dis. 2009;9:16.

4. Van Der Pol B. Sexually transmitted infections in women. Scand J Clin Lab Invest Suppl. 2014;244:68-74; discussion 3.

5. Farley TA, Cohen DA, Elkins W. Asymptomatic sexually transmitted diseases: the case for screening. Prev Med. 2003;36:502-9.

6. Kim SJ, Lee DS, Lee SJ. The prevalence and clinical significance of urethritis and cervicitis in asymptomatic people by use of multiplex polymerase chain reaction. Korean J Urol. 2011;52:703-8.

7. Solomon D. The Bethesda System for reporting cervical/vaginal cytologic diagnosis: an overview. Int J Gynecol Pathol. 1991;10:323-5.

8. Chun JY, Kim KJ, Hwang IT, Kim YJ, Lee DH, Lee IK, et al. Dual priming oligonucleotide system for the multiplex detection of respiratory viruses and SNP genotyping of CYP2C19 gene. Nucleic Acids Res. 2007;35:e40.

9. De Francesco MA, Caracciolo S, Bonfanti C, Manca N. Incidence and antibiotic susceptibility of Mycoplasma hominis and Ureaplasma urealyticum isolated in Brescia, Italy, over 7 years. J Infect Chemother. 2013;19:621-7.

10. Pisani S, Gallinelli C, Seganti L, Lukic A, Nobili F, Vetrano G, et al. Detection of viral and bacterial infections in women with normal and abnormal colposcopy. Eur J Gynaecol Oncol. 1999;20:69-73.

11. Zhang D, Li T, Chen L, Zhang X, Zhao G, Liu Z. Epidemiological investigation of the relationship between common lower genital tract infections and high-risk human papillomavirus infections among women in Beijing, China. PLoS One. 2017;12:e0178033.

12. Szostek S, Wojtys A, Zgorniak-Nowosielska I. Papilloma virus infections in women with cervical pathology. Med Dosw Mikrobiol. 1993;45:133-6.

13. Zheng MY, Zhao HL, Di JP, Lin G, Lin Y, Lin X, et al. Association of human papillomavirus infection with other microbial pathogens in gynecology. Zhonghua Fu Chan Ke Za Zhi. 2010;45:424-8.
14. Biernat-Sudolska $\mathrm{M}$, Szostek $\mathrm{S}$, Rojek-Zakrzewska $\mathrm{D}$, Klimek $\mathrm{M}$, Kosz-Vnenchak M. Concomitant infections with human papillomavirus and various mycoplasma and ureaplasma species in women with abnormal cervical cytology. Adv Med Sci. 2011;56:299-303.

15. Xiaolei $\mathrm{C}$, Taot $\mathrm{H}$, Zongli S, Hongying $\mathrm{Y}$. The role of ureaplasma urealyticum infection in cervical intraepithelial neoplasia and cervical cancer. Eur J Gynaecol Oncol. 2014;35:571-5.

16. Camporiondo MP, Farchi F, Ciccozzi M, Denaro A, Gallone D, Maracchioni F, et al. Detection of HPV and co-infecting pathogens in healthy Italian women by multiplex real-time PCR. Infez Med. 2016;24:12-7.

17. Drago F, Herzum A, Ciccarese G, Dezzana M, Casazza S, Pastorino A, et al. Ureaplasma parvum as a possible enhancer agent of HPV-induced cervical intraepithelial neoplasia: Preliminary results. J Med Virol. 2016;88:2023-4.

18. Liu J, Liu W, Liu Y, Zhou X, Zhang Z, Sun Z. Prevalence of microorganisms co-infections in human papillomaviruses infected women in Northern China. Arch Gynecol Obstet. 2016;293:595-602.

19. Okodo M, Kawamura J, Okayama K, Kawai K, Fukui T, Shiina N, et al. Cytological Features Associated with Ureaplasma Urealyticum in Pap Cervical Smear. Asian Pac J Cancer Prev. 2017;18:2239-42.

20. Szostek S, Zawilinska B, Biernat-Sudolska M, Kopec J, Kleszcz E, Koprynia M, et al. Differences in the expression of human papillomavirus type 16 (HPV-16) E6 oncogene mRNA in SiHa cell line inoculated with CMV, HSV or ureaplasmas. Folia Biol (Krakow). 2014;62:73-8.

21. Kataja V, Syrjanen S, Yliskoski M, Hippelinen M, Vayrynen M, Saarikoski S, et al. Risk factors associated with cervical human papillomavirus infections: a case-control study. Am J Epidemiol. 1993;138:735-45.

22. Bhatla N, Puri K, Joseph E, Kriplani A, Iyer VK, Sreenivas V. Association of Chlamydia trachomatis infection with human papillomavirus (HPV) \& cervical intraepithelial neoplasia - a pilot study. Indian J Med Res. 2013;137:533-9.

23. Scheurer ME, Tortolero-Luna G, Adler-Storthz K. Human papillomavirus infection: biology, epidemiology, and prevention. Int J Gynecol Cancer. 2005;15:727-46.

24. Samoff E, Koumans EH, Markowitz LE, Sternberg M, Sawyer MK, Swan D, et al. Association of Chlamydia trachomatis with persistence of high-risk types of human papillomavirus in a cohort of female adolescents. Am J Epidemiol. 2005;162:668-75.

25. Zhang N, Wang R, Li X, Liu X, Tang Z, Liu Y. Are Ureaplasma spp. a cause of nongonococcal urethritis? A systematic review and meta-analysis. PLoS One. 2014;9:e113771.

26. Liu L, Cao G, Zhao Z, Zhao F, Huang Y. High bacterial loads of Ureaplasma may be associated with non-specific cervicitis. Scand J Infect Dis. 2014;46:637-41.

27. Hunjak B, Sabol I, Vojnovic G, Fistonic I, Erceg AB, Persic Z, et al. Ureaplasma urealyticum and Ureaplasma parvum in women of reproductive age. Arch Gynecol Obstet. 2014;289:407-12.

28. Vargovic M, Pasini M, Papic N, Andrasevic S, Markotic A, Butic I, et al. Antimicrobial susceptibility of Ureaplasma urealyticum and Mycoplasma hominis. Sex Transm Infect. 2014;90:69.

29. Lee DS, Choe HS, Lee SJ, Bae WJ, Cho HJ, Yoon BI, et al. Antimicrobial susceptibility pattern and epidemiology of female urinary tract infections in South Korea, 2010-2011. Antimicrob Agents Chemother. 2013;57:5384-93.

30. Xie X, Zhang J. Trends in the rates of resistance of Ureaplasma urealyticum to antibiotics and identification of the mutation site in the quinolone resistance-determining region in Chinese patients. FEMS Microbiol Lett. 2006;259:181-6. 